\title{
Smart City Evaluation Based on Analytic Hierarchy Process

\author{
Xinyu Xing
}

North China Electric Power University Baoding, Baoding 071003, China;

374701837@qq.com

Keywords: smart growth, success, index

\begin{abstract}
We combine literature review and three E's to select more reasonable evaluation index. We establishes three primary indicators (Economic Success ,Social Success, Environmental Success)and twelve secondary measures by referring to the smart urban evaluation index system of the EU, IBM, Nanjing and Tai- wan. From the analysis and the calculation results, it is reasonable for our metric to measure the success of smart growth of a city. Our MSGC is suitable for the evaluation of smart city growth and provides reference for government policy makers.
\end{abstract}

\section{Introduction}

The sustainable development of cities, as a new concept of the construction of the global cities, makes up for the shortage and defects of the theory of city development, and provides a new theory and method for the healthy development of cities. How to realize the sustainable development of the cities is one of the most important subjects in the world. However, there is no existing standardized models that could help ICM apply the theory of smart growth to cities around the world. Thus, our task is to build a model to provide a method for cities to measure the success of smart growth of cities. Therefore, we build Model MSGC to measure the success of smart growth of a city .

\section{Index selection}

We establishes three primary indicators (Economic Success ,Social Success, Environmental Success)and twelve secondary measures by referring to the smart urban evaluation index system of the EU, IBM, Nanjing and Tai- wan .Thus, our index evaluation system finishes.

\section{Index system}

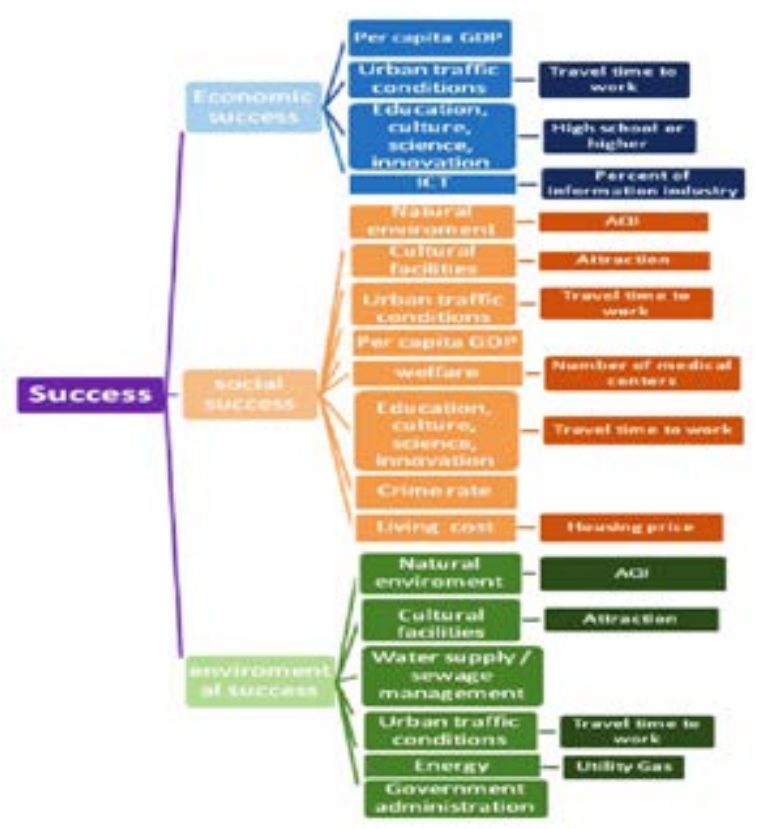




\section{Index weighing}

In the three factors that determine the overall target judgment matrix, we refer to the study of Wang[1] , assuming that social success has the greatest impact on the overall judgment matrix, while economic success has the least effect. We can get the judgment matrix of the evaluation index system.

Table 1 Overall target judgment matrix

\begin{tabular}{|c|c|c|c|}
\hline S & W1 & W2 & W3 \\
\hline W1 & 1 & 0.2 & 0.25 \\
\hline W2 & 5 & 1 & 1.25 \\
\hline W3 & 4 & 0.8 & 1 \\
\hline
\end{tabular}

Table 2 W1 judgment matrix

\begin{tabular}{|l|l|l|l|l|}
\hline W1 & W1 1 & W12 & W13 & W14 \\
\hline W1 1 & 1 & 5 & 5 & 5 \\
\hline W12 & 0.2 & 1 & 1 & 1 \\
\hline W13 & 0.2 & 1 & 1 & 1 \\
\hline W14 & 0.2 & 1 & 1 & 1 \\
\hline
\end{tabular}

Table 3 W2 judgment matrix

\begin{tabular}{|c|c|c|c|c|c|c|c|c|}
\hline W2 & W21 & W22 & W23 & W24 & W25 & W26 & W27 & W28 \\
\hline W21 & 1 & $5 / 7$ & 1.25 & $5 / 3$ & $1 / 3$ & $5 / 3$ & $5 / 7$ & 1 \\
\hline W22 & 1.4 & 1 & $7 / 4$ & $7 / 3$ & $7 / 15$ & $7 / 3$ & 1 & $7 / 5$ \\
\hline W23 & 0.8 & $4 / 7$ & 1 & $4 / 3$ & $4 / 15$ & $4 / 3$ & $4 / 7$ & $4 / 5$ \\
\hline W24 & $3 / 5$ & $3 / 7$ & $3 / 4$ & 1 & $1 / 5$ & 1 & $3 / 7$ & $3 / 5$ \\
\hline W25 & 3 & $15 / 7$ & $15 / 4$ & 5 & 1 & 5 & $15 / 7$ & 3 \\
\hline W26 & $3 / 5$ & $3 / 7$ & $3 / 4$ & 1 & $1 / 5$ & 1 & $3 / 7$ & $3 / 5$ \\
\hline W27 & $7 / 5$ & 1 & $7 / 4$ & $7 / 3$ & $7 / 15$ & $7 / 3$ & 1 & $7 / 5$ \\
\hline W28 & 1 & $5 / 7$ & $5 / 4$ & $5 / 3$ & $1 / 3$ & $5 / 3$ & $5 / 7$ & 1 \\
\hline
\end{tabular}

Table 4 W3 judgment matrix

\begin{tabular}{|c|c|c|c|c|c|c|}
\hline W3 & W31 & W32 & W33 & W34 & W35 & W36 \\
\hline W31 & 1 & $11 / 5$ & $11 / 10$ & $11 / 7$ & $11 / 5$ & $11 / 5$ \\
\hline W33 & $5 / 11$ & 1 & $1 / 2$ & $5 / 7$ & 1 & 1 \\
\hline W34 & $7 / 11$ & $7 / 5$ & $7 / 10$ & 1 & $7 / 5$ & $7 / 5$ \\
\hline W35 & $5 / 11$ & 1 & $1 / 2$ & $5 / 7$ & 1 & 1 \\
\hline W36 & $5 / 11$ & 1 & $1 / 2$ & $5 / 7$ & 1 & 1 \\
\hline
\end{tabular}

According to the judgment matrix to obtain the weight table 
Table 5 weight table

\begin{tabular}{|c|c|c|}
\hline & weight value & $\begin{array}{c}\text { Max } \\
\text { eigen- } \\
\text {-value }\end{array}$ \\
\hline$A \mathrm{~s}=\left\{\mathrm{a}_{\mathrm{w} 1}, \mathrm{a}_{\mathrm{w} 2}, \mathrm{a}_{\mathrm{w} 3}\right\}^{\mathrm{T}}$ & $\{0.1,0.5,0.4\}^{T}$ & 3 \\
\hline$A_{w 2}=\left\{a_{w 21}, a_{w 22}, a_{w 23}, a_{w 24}, a_{w 25}, a_{w 26}, a_{w 27}\right.$ & $\{0.1020,0.1429,0.0816,0.0612,0.3061,0.0612,0.1429,0.1020\}^{T}$ & 4 \\
\hline$A_{w 3}=\left\{a_{w 31}, a_{w 32}, a_{w 33}, a_{w 34}, a_{w 35}, a_{w 36}\right\}^{T}$ & $\{0.2558,0.1163,0.2326,0.1628,0.1163,0.1163\}^{T}$ & 8 \\
\hline$A_{\mathrm{w} 1}=\left\{\mathrm{a}_{\mathrm{w} 11}, \mathrm{a}_{\mathrm{w} 12}, \mathrm{a}_{\mathrm{w} 13}, \mathrm{a}_{\mathrm{w} 14}\right\}^{\mathrm{T}}$ & $\{0.625,0.125,0.125,0.125\}^{T}$ & 6 \\
\hline \multicolumn{3}{|c|}{$\begin{array}{l}S=A_{i} * \sum_{j=1}^{n}\left(A_{i j} * W_{i j}\right) \\
S=0.1 * W_{1}+0.5 * W_{2}+0.4 * W_{3} \\
W_{1}=0.625 * W_{11}+0.125 * W_{12}+0.125 * W_{13}+0.125 * W_{14} \\
W_{2}=0.1020 * W_{21}+0.1429 * W_{22}+0.0816 * W_{23}+0.0612 * W_{24}+0.3061 * W_{25} \\
+0.0612 * W_{26}+0.1429 * W_{27}+0.1020 * W_{28} \\
W_{3}=0.2558 * W_{31}+0.1163 * W_{32}+0.2326 * W_{33}+0.1628 * W_{34}+0.1163 * W_{35} \\
+0.1163 * W_{36}\end{array}$} \\
\hline
\end{tabular}

where: $\mathrm{S}$ is the total success of the city.Ai is the weight of the primary index,

and Aij is the weight of the secondary index. Wij is the success of every index which is impressed in $1,0,-1$.

Consistency check list

There is no need for consistency test between Second order and second order below.

Table 6 consistency check list

\begin{tabular}{|c|c|c|c|c|}
\hline & $\mathrm{S}$ & $\mathrm{W} 1$ & $\mathrm{~W} 2$ & $\mathrm{~W} 3$ \\
\hline $\mathrm{CI}$ & 0.0004 & 0.0067 & 0.0009 & 0.0010 \\
\hline $\mathrm{CR}$ & 0.0117 & 0.0134 & 0.0120 & 0.0127 \\
\hline
\end{tabular}

\section{Results}

According to the calculated results, $\mathrm{CR}=0 \leq 0.1$,so the judgment matrix satisfies the consistency, and the weight distribution is reasonable.

\section{Summary:}

From the analysis and the calculation results, our metric to measure the success of smart growth of a city is reasonable. Our MSGC is suitable for the evaluation of smart city growth and provides reference for government policy makers.

\section{References:}

[1] Wang sixue and Zhen Lei, "Comparison of evaluation index system of intelligent cities at home and abroad,” E-government, no. 1, pp. 92-100, 2013.

[2] Nuwan Dias, Steve Curwell, and Erik Bichard, "The current approach of urban design, its implications for sustainable urban development ," Procedia Economics and Finance, vol. 18,pp.497-504, 2014.

[3]Zhang juan and L. I. Jiang-Feng, "The enlightenment from american” smart growth" on the Spatial extent of the cities in our country, " Municipal Administration and Technology, 2006. 
[4] Yi Hua, Chu Dajian, and Liu Donghua, "Urban transformation: from linear growth to smart growth. price theory and practice,” Price theory and Practice,no.7.pp.66-67, 2006.

[5] L. Dan, "Resourcecbased city sustainable development ability evaluation method utilizing bp neural network,” Journal of Chemical \& Pharmaceution, Research,2014. 